\title{
A caminhar para uma escola inclusiva em Portugal: os desafios sentidos pelos profissionais dos contextos educativos
}

\author{
Towards an inclusive school in Portugal: the challenges experienced by \\ professionals in educational contexts
}

\section{Caminando hacia una escuela inclusiva en Portugal: los desafíos que experimentan los profesionales en contextos educativos}

\author{
Débora Carolina Abreu \\ Mestra pela Universidade do Porto, Porto, Portugal \\ E-mail: deboraabreu@fpce.up.pt ORCID: https://orcid.org/0000-0002-0531-4047 \\ Catarina Grande \\ Professora doutora da Universidade do Porto, Porto, Portugal \\ E-mail: cgrande@fpce.up.pt ORCID: https://orcid.org/0000-0003-4675-6279
}

Recebido em 18 de junho de 2020

Aprovado em 23 de abril de 2021

Publicado em 27 de maio de 2021

\section{RESUMO}

A 6 de julho de 2018 foi promulgado o Decreto-lei 54/2018 revogando o anterior Decretolei 3/2008 que regulamentava a Educação Especial em Portugal. Em prol de uma escola verdadeiramente inclusiva, surge um quadro legal alinhado com uma visão holística e com uma abordagem contínua e integrada do percurso escolar. Como consequência desta alteração legislativa, surgiu o interesse por estudar este momento de transição vivenciado pelos profissionais nos contextos educativos. Através de uma metodologia qualitativa, com recurso a entrevistas semiestruturadas a 17 profissionais de contextos educativos portugueses, e à posterior análise categorial do seu conteúdo, procurámos compreender quais as dificuldades e soluções que estes/as profissionais apontavam neste momento inicial de transição legislativa. As categorias identificadas, basearam-se nos aspetos relevantes para os objetivos do estudo, nos conceitos e temas sugeridos pela literatura, e nas questões da entrevista. Foram identificadas diversas dificuldades, tais como, a falta de recursos (e.g., falta de formação, falta de tempo), a demarcação da legislação anterior e o ajustamento à nova definição de papéis por parte de toda a comunidade educativa (incluindo as famílias), e fatores de natureza macrossistémica como as características da classe docente e as incongruências nas informações disponibilizadas e nas exigências. Já como soluções, apontaram: apoio no domínio formativo, apoio emocional e apoio logístico (e.g., recursos humanos). Estes resultados indicam que, segundo estes/as profissionais, este foi um processo de transição pautado por diversas dificuldades passíveis de serem colmatadas pela agência conjunta de todos, desde instâncias superiores, estruturas intermédias, profissionais dos contextos educativos e famílias.

Palavras-chave: escola inclusiva; políticas educativas em Portugal; inclusão. 
http://dx.doi.org/10.5902/1984686X47438

\section{ABSTRACT}

On July 6, 2018, Decree-Law (DL) 54/2018 was enacted revoking the previous Decree-Law 3/2008 that regulated Special Education in Portugal. In favor of a truly inclusive school, a legal framework appears, aligned with a holistic view and with a continuous and integrated approach to the school path. Because of this legislative change, there was an interest in studying this initial moment of transition experienced by professionals in educational contexts. Through a qualitative methodology, using semi-structured interviews with 17 professionals from Portuguese educational contexts, and the subsequent categorical analysis of its content, there was an attempt to understand what difficulties and solutions these professionals encountered in this initial moment of transition. The identified categories were based on relevant aspects to the study's aims, on the concepts and themes suggested by literature, and on the interview questions. Several difficulties were identified, such as the lack of resources (e.g., lack of training; lack of time), the demarcation of previous legislation and the adjustment of the new roles' definition by the entire educational community (including families), and factors of a macrosystemic nature such as the characteristics of the teaching category, and the inconsistencies in the information provided and in the requirements. As for solutions, they pointed out: support in the training domain, emotional support, and logistical support (e.g., human resources). These results indicate that, according to these professionals, this was a transition process marked by several difficulties that can be overcome by everyone's joint agency: higher levels, intermediate structures, educational professionals and families.

Keywords: inclusive school; educational policies in Portugal; inclusion.

\section{RESUMEN}

El 6 de julio de 2018, se promulgó el Decreto Ley (DL) 54/2018 que revoca el anterior DL 3/2008 que regulaba la Educación Especial en Portugal. A favor de una escuela verdaderamente inclusiva, aparece un nuevo marco legal, alineado con una visión holística y con un enfoque continuo e integrado del camino escolar. Como consecuencia de este cambio legislativo, hubo interés en estudiar este momento inicial de transición experimentado por los profesionales en contextos educativos. A través de una metodología cualitativa, mediante entrevistas semiestructuradas a 17 profesionales de contextos educativos portugueses, y el posterior análisis categórico de su contenido, se buscó comprender qué dificultades y soluciones apuntaban estos profesionales en este momento inicial de transición legislativa. Las categorías identificadas se basaron en aspectos relevantes para los objetivos del estudio, en los conceptos y temas sugeridos por la literatura y en las preguntas de la entrevista. Se identificaron varias dificultades, como la falta de recursos, la demarcación de la legislación anterior y el ajuste de la nueva definición de roles por parte de toda la comunidad educativa (incluidas las familias), y factores de carácter macro sistémico como las características de la clase docente y las inconsistencias en la información proporcionada y en los requisitos. Como soluciones, señalaron: apoyo en el dominio de la formación, apoyo emocional y apoyo logístico. Estos resultados indican un proceso de transición marcado por varias dificultades que lo trabajo conjunto de todos (niveles superiores, estructuras intermedias, profesionales de contextos educativos y familias) puede superar.

Palabras clave: escuela inclusiva; políticas educativas en Portugal; inclusión. 
http://dx.doi.org/10.5902/1984686X47438

\section{Introdução}

A forma de olhar e de refletir a diferença foi-se alterando a par de transformações sociais, culturais e políticas. Em Portugal, à semelhança de outros países, nas últimas 3 décadas viveu-se o Período Educar e Incluir (SHONKOFF \& MEISELS, 2000) impulsionado pela publicação da Declaração de Salamanca (Organização das Nações Unidas para a Educação, a Ciência e a Cultura; UNESCO, 1994), cujas diretrizes orientam o papel fundamental da escola na educação e de outras instituições e serviços que intervêm de forma (in)direta no processo de formação e aprendizagem das crianças ${ }^{1}$. Com a publicação desta declaração, surgiu o conceito de escola inclusiva sobre o qual se tem verificado um maior investimento, através da procura de estratégias que potenciem a inclusão de crianças com necessidades educativas especiais (NEE) nos contextos escolares.

Em Portugal, os esforços para integrar crianças com deficiência nas escolas já se verificam desde a segunda metade do século XX, principalmente após o 25 de abril de 1974 (fim da ditadura) em que todas as crianças passaram a ter o direito de acesso à escola. No ano letivo de 1975/1976 foram implementadas as equipas de Educação Especial nas escolas, para que as crianças com deficiências motoras e sensoriais tivessem apoio e, posteriormente, foram integradas também crianças com deficiências mentais nas escolas regulares. Em 1986, ocorreram dois eventos importantes neste percurso: Portugal entrou na $\mathrm{CEE}^{2}$ e foram disponibilizados mais apoios para a promoção de iniciativas no sentido de apoiar as crianças com deficiência; e foi publicada a Lei de Bases do Sistema Educativo que oficializou a integração do ensino especial no sistema de ensino português. Em 1991, influenciado pelo Warnock Report (1978), foi promulgado o decreto-lei (DL) 319/91 que, além de regulamentar a frequência de alunos com NEE nos estabelecimentos públicos de ensino básico e secundário, propôs algumas alterações significativas: substituir o conceito de deficiência por NEE; promover a utilização de uma abordagem educacional na descrição das dificuldades destas crianças; enfatizar o papel da família no processo educativo; e responsabilizar a escola pela integração de todas as crianças. Já no fim da década de 90, foi publicada a Lei-Quadro da Educação Pré-escolar 5/97, que definia o pré-escolar como o primeiro nível ensino, destacando, assim, a importância do acesso à escola o mais precocemente possível.

Posteriormente, foi publicado o DL 6/2001 que possibilitava aos alunos ${ }^{3}$ com NEE de caráter permanente o acesso à modalidade de educação especial e diferenciava o insucesso escolar repetido, os problemas de integração na comunidade educativa e as NEE de caráter 
http://dx.doi.org/10.5902/1984686X47438

permanente, impulsionando a diversificação das ofertas curriculares com o objetivo de combater a exclusão. Outro contributo neste sentido, após ter sido regulamentada, em 2002, a componente letiva dos docentes da educação especial, do ensino especial e outros docentes especializados que prestavam apoio desde o pré-escolar ao ensino secundário, foi a aprovação do $1^{\circ}$ Plano de Ação para a Integração de Pessoas com Deficiência ou Incapacidade em 2006. Este plano contemplou a atribuição de apoios cruciais para a reabilitação e inclusão de pessoas com deficiência ou incapacidade, tais como a disponibilização de manuais escolares digitais para alunos cegos ou com baixa visão (Resolução do Conselho de Ministros n.․ 120/2006).

Em 2008, em Portugal, foi promulgado o DL 3/2008, de 7 de janeiro, no qual a visão médica foi substituída por uma abordagem focada no perfil de funcionalidade dos alunos, salientando a relevância do seu envolvimento e participação nos seus contextos, e introduzindo a utilização da Classificação Internacional da Funcionalidade Incapacidade e Saúde: versão para Crianças e Jovens (CIF-CJ) (ORGANIZAÇÃO MUNDIAL DE SAÚDE; WHO, 2007) na realização da avaliação especializada, imprescindível na ponderação da elegibilidade da criança no que respeita ao benefício de apoio especializado na modalidade da educação especial (EE) (SANCHES-FERREIRA et al., 2014). Este foi o principal documento legal que regulamentou a frequência das crianças com NEE nas escolas e, embora revisto e alterado ao longo dos anos, vigorou em Portugal até julho de 2018.

Com a promulgação do Despacho-Conjunto n. 0 13170/2009, as turmas nas quais estivessem afetos alunos com NEE apenas poderiam ter um máximo de 20 alunos e dois alunos com NEE na sua constituição. Ainda no mesmo ano, foi publicado o DL 281/2009 que oficializou a criação do $\mathrm{SNIPI}^{4}$ cujo objetivo se prendia com, através de uma ação intersectorial, prestar apoio a crianças (e suas famílias) com idades compreendidas entre os 0 e os 6 anos que se encontrem em risco grave de atraso desenvolvimental ou que possuam alterações nas funções ou estruturas do corpo que tenham implicação negativa na sua participação em atividades típicas para a sua idade e contexto social. Já em 2012, foi promulgada a Portaria no 275-A/2012 centrada no ensino dos alunos com currículos específicos individuais (CEI) em processo de transição para a vida pós-escolar, estabelecendo a implementação de um Plano Individual de Transição (PIT) e incentivando ao estabelecimento de protocolos com Centros de Recursos para a Inclusão (CRI).

Em 2014, após ter sido aprovado o Grupo de Trabalho para a revisão do quadro legal vigente à data, relativamente à educação especial, foi publicada a Recomendação n. 0 1/2014, 
http://dx.doi.org/10.5902/1984686X47438

na qual destacaram diversos problemas, tais como os critérios de elegibilidade do DL 3/2008, a operacionalização da Portaria nำ275-A/2012 e do SNIPI, e a utilização da CIF5 . No sentido colmatar os aspetos apontados, em 2015 foi publicada a Resolução da Assembleia da República n. 17/2015 que contemplou múltiplas alterações, nomeadamente: no adiamento autorizado da entrada na escolaridade; na disponibilização de medidas educativas em momentos de avaliação externa para crianças com NEE; certificação pedagógica do percurso escolar para alunos com medidas $\mathrm{PEI}^{6}$ e CEI; considerar NEE de caráter transitório e dificuldades de aprendizagem; e, ainda, a disponibilização de uma medida educativa que permitisse a adaptação do currículo de modo mais flexível do que a medida CEI. Ainda, foi

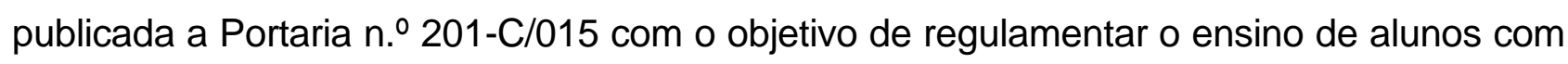
15 ou mais anos no sentido de lhes ser proporcionado um ensino atualizado e que contemplasse a articulação entre a escola e outras organizações da comunidade, por exemplo, no que respeita à reordenação de recursos.

Em 2016 foram publicadas as "Orientações Curriculares para a Educação Pré-Escolar" com o propósito de orientar a gestão do currículo no jardim-de-infância, com o objetivo da promoção de coerência no sistema educativo e continuidade educativa. Entre 2016 e 2018 foram publicados os documentos que constituem o quadro legal atual: a Estratégia Nacional de Educação para a Cidadania (ENEC); o Perfil dos Alunos à Saída da Escolaridade Obrigatória (PA); as Aprendizagens Essenciais; o DL 54/2018; e o DL 55/2018.

É considerado que, atualmente, se vive um novo paradigma na Educação em Portugal, não apenas pela publicação dos documentos supracitados, mas particularmente pela promulgação do DL 54/2018 que tem por objetivo uma escola que se traduza num "local onde todos têm direito a aprender, através de um currículo que leva cada aluno ao limite das suas capacidades" (COSTA, 2018, p.4 cit. in EUROPEAN AGENCY, 2018). O DL 54/2018 que inspirou este estudo define os princípios orientadores para que a inclusão seja garantida, considerando-a como um processo que responde à panóplia de necessidades de todos e cada um dos alunos (art. 1.ํ) e identificando as medidas de suporte à aprendizagem e à inclusão, as áreas curriculares específicas e os recursos a mobilizar nesse sentido (art. 2.ำ). Estas medidas de suporte à aprendizagem encontram-se organizadas segundo uma abordagem multinível, e serão adotadas mediante a resposta dos alunos a essas estratégias que diferem em termos de tipo, intensidade e frequência: as medidas universais (nível 1) são práticas/serviços disponibilizados com o objetivo de potenciar o sucesso e aprendizagem de todos os alunos; as medidas seletivas (nível 2) são práticas/serviços disponibilizados aos 
http://dx.doi.org/10.5902/1984686X47438

alunos em situações de risco ou que demonstram necessitar de apoio complementar (e.g., intervenções em pequeno grupo e, tendencialmente, de curta duração); as medidas adicionais (nível 3) são intervenções com maior frequência, intensidade e tempo de implementação, que são desenhadas para cada aluno de acordo com as suas potencialidades e necessidades, e implementadas individualmente ou em pequenos grupos.

Este decreto propõe cinco grandes alterações alinhadas com uma visão holística de inclusão e uma abordagem integrada e contínua do percurso escolar (DGE, 2018): o afastamento da categorização dos alunos, nomeadamente na categoria das NEE; 0 afastamento do modelo da legislação especial para os alunos especiais; o estabelecimento de um continuum de respostas para todos os alunos; o foco nas respostas educativas; e a perspetiva da mobilização complementar, sempre pertinente, de recursos de segurança social, saúde, formação profissional ou de emprego. Além destas alterações, reconfigura o modelo de Unidade Especializada (integrando-o num modelo de Centro de Apoio à Aprendizagem), destaca a importância da participação de todos os agentes envolvidos no processo educativo (nomeadamente através da criação das Equipas Multidisciplinares de Apoio à Educação Inclusiva (EMAEI)) e reforça a importância do papel dos pais/encarregados de educação no processo educativo (DGE, 2018). Estas alterações propostas pelo DL 54/2018 sugerem uma mudança de paradigma, cujo foco se prende com a universalidade da escola, desenvolvendo assim uma "escola inclusiva de segunda geração" (ALVES, 2019, p.4) que valoriza a diversidade e a individualidade de cada aluno. Este decreto considera fatores de natureza académica, comportamental, social, emocional e ambiental inscritos na multidimensionalidade do conceito de inclusão. De acordo com Costa (2018 cit. in EUROPEAN AGENCY, 2018), esta legislação não se foca nas incapacidades, exclui categorizações (e, consequentemente, o rótulo de educação especial), e foca-se na dificuldade que os alunos demonstram em aceder ao currículo e em realizar aprendizagens significativas seja por motivos de incapacidade, socioeconómicos ou emocionais para que se melhore a inclusão e, consequentemente, a qualidade da educação ao longo da escolaridade obrigatória em Portugal (Decreto-lei 54/2018).

De modo a promover o sucesso de uma escola inclusiva, é necessário que haja adaptação nos diversos domínios da educação formal, nomeadamente no currículo, nos métodos de avaliação, na pedagogia (que deverá ser centrada na criança), na ética escolar, nas atividades extracurriculares, assim como nas instalações e organização escolar (ONU, 1994). Nesta lógica, e a par com a promulgação do DL 54/2018, foi publicado o DL 55/2018 
que define um novo currículo para os ensinos básico e secundário que estabelece princípios orientadores para a conceção, operacionalização e avaliação das aprendizagens (art. 1.ํ). É pretendido, de acordo com o decreto, a apropriação plena da autonomia curricular por parte da escola, de modo a que sejam criadas condições para que todos os alunos adquiram conhecimentos e capacidades que os levem a alcançar as competências que fazem parte do PA (Decreto-lei 55/2018).

À medida que esta legislação foi sendo implementada, foram detetados aspetos menos funcionais (e.g., esclarecimento/definição concreta de papéis) e começaram a surgir múltiplas propostas de alteração. A partir da discussão dessas propostas, foi promulgada a Lei 116/2019, de 13 de setembro, que não só abrange alterações no DL 54/2018, como também efetiva a republicação do mesmo.

As escolas em Portugal são marcadas por uma grande heterogeneidade e, atualmente, encontram-se presentes cerca de 198 nacionalidades distintas (PEREIRA, 2019). No ano letivo de 2017/2018, de acordo com o relatório "Pessoas com Deficiência em Portugal Indicadores de Direitos Humanos 2018" (PINTO \& PINTO, 2018), matricularam-se 88.023 alunos com NEE, o que reflete um aumento de $6 \%$ relativamente ao ano letivo anterior. Estes dois exemplos ilustram como a inclusão, além de um imperativo ético (PEREIRA, 2018), é urgente e deve ser mais abrangente do que nunca. É, assim, um processo não só respeitante à educação, mas um processo também a nível político e social pelo que, além de ser um direito fundamental do ser humano, implica um repensar tanto da escola como da diferença e da diversidade, constituindo-se como "um veículo para a transformação da sociedade" (FREIRE, p.8, 2008).

\section{Método}

\section{Objetivos do estudo}

O decreto-lei que fundamentou a realização deste estudo foi publicado em Diário da República a 6 de julho de 2018 e entrou em vigor em setembro do mesmo ano (início do ano letivo 2018/2019). Deste modo, com o presente estudo pretendeu-se compreender as vivências, desafios e necessidades sentidos pelos profissionais que se encontram a trabalhar nos contextos escolares num primeiro momento da implementação desta legislação (momento de transição entre legislações) e, ainda, averiguar que soluções 
http://dx.doi.org/10.5902/1984686X47438

consideravam que poderiam colmatar essas mesmas dificuldades. Assim, pretendeu-se responder a duas questões de investigação:

Q1: Quais os principais desafios e dificuldades identificados quer a título individual, quer a nível coletivo por estes profissionais no momento inicial da implementação do DL54/2018?

Q2: Quais as soluções que propõem para uma melhor e mais eficaz implementação da nova legislação?

\section{Participantes}

Participaram no presente estudo 17 profissionais na área da educação a exercer a sua atividade profissional na área do Grande Porto (Portugal). Este grupo de informantes é constituído por: 8 docentes de educação especial (DEE) (três coordenadoras da EMAEI no seu agrupamento); 3 docentes titulares de turma (Dt); 1 diretor de turma (DT); e 4 psicólogas (PSI) do serviço de psicologia e orientação dos agrupamentos (1 coordenadora da EMAEI e 1 psicóloga de um Centro de Recursos para a Inclusão). Estes profissionais têm idades compreendidas entre os 29 e os 56 anos $(M=45.70$; $D P=8.42)$, com uma média de, aproximadamente, 20 anos de serviço.

Os participantes foram selecionados através de uma técnica de amostragem não probabilística, o efeito bola de neve, na qual os indivíduos selecionados para participarem no estudo convidam novos participantes da sua rede de amigos e conhecidos (WATERS, 2015). Atendendo aos critérios de saturação teórica (BAUER \& GASKELL, 2002), que se traduz na não introdução de novas informações significativas por parte dos participantes, foi dado por terminado o processo de recrutamento.

\section{Medidas e procedimentos}

Para a recolha dos dados foram realizadas entrevistas semi-estruturadas, que seguiram um guião elaborado para o efeito. Este guião foi pilotado em novembro de 2018, tendo sido as restantes entrevistas realizadas entre janeiro e maio de $2019,2 .$. período do ano letivo 2018/2019, por forma a permitir algum tempo entre o início da implementação da nova legislação e a recolha dos dados, possibilitando uma maior familiarização com a mesma.

A técnica selecionada para o tratamento de informação, atendendo ao número de entrevistas (POIRIER, VALLADON, \& RAYBAUT, 1999) e aos objetivos supracitados, foi a análise de conteúdo. Lima e Pacheco (2006) referem que a par da análise estatística, a 
http://dx.doi.org/10.5902/1984686X47438

análise de conteúdo é o procedimento mais utilizado no âmbito das ciências sociais, uma vez que permite refletir sobre diferentes discursos. Assim, a análise de conteúdo é um método que possibilita ao investigador testar questões teóricas e melhorar a compreensão dos dados obtidos (ELO \& KYNGÄS, 2007), agrupando-os com vista a identificar consistências e significados centrais (PATTON, 1990), permitindo uma análise dedutiva e/ou indutiva (ELO \& KYNGÄS, 2007).

Numa primeira fase, as entrevistas foram transcritas e posteriormente revistas para a correção de eventuais erros. Segundo Bardin (2011), destacam-se três fases da análise de conteúdo: a pré-análise, a exploração do material e, por fim, o tratamento dos resultados, a inferência e a interpretação.

Numa fase inicial, de pré-análise, procedeu-se a uma leitura flutuante das transcrições das entrevistas selecionadas atendendo à regra da pertinência (BARDIN, 2011), o que permitiu um melhor conhecimento e o aumento de familiaridade com o texto, assim como o estabelecimento de impressões e orientações relativas ao mesmo. Durante este processo inicial, duas entrevistas foram analisadas separadamente por duas investigadoras que, num momento posterior, discutiram em conjunto as ideias que emergiram desse processo de reflexão e da análise do conteúdo. Este momento permitiu a definição inicial de um quadro de categorias e subcategorias que foram identificadas através de uma análise dedutiva e indutiva. Posteriormente, elaborou-se o quadro de categorização, essencial para clarificar o conteúdo das informações recolhidas, permitindo fazer inferências e, posteriormente, fazer uma interpretação dos dados obtidos. Segundo Bardin (2011), esta inferência possibilita uma passagem da descrição à interpretação, através da atribuição de um sentido às caraterísticas do material recolhido.

No que diz respeito à escolha das categorias, estas basearam-se nos aspetos relevantes para os objetivos do estudo, nos conceitos e temas sugeridos pela literatura, bem como nas questões da entrevista.

\section{Resultados e discussão}

De seguida serão apresentados e discutidos os resultados obtidos relativamente às duas questões de investigação.

Quanto à Q1, relativa aos desafios e dificuldades identificadas, surgiram 12 categorias principais (falta de formação $(n=10)$; falta de tempo $(n=4)$; falta de recursos humanos $(n=3)$; demarcação da legislação anterior/mudança de paradigma $(n=4)$; 
http://dx.doi.org/10.5902/1984686X47438

definição de papéis $(n=8)$; envolvimento da família $(n=8)$; dimensão pessoal dos alunos com NSA/obrigatoriedade de permanência na sala de aula $(n=5)$; dimensão pessoal dos docentes do regular; características da classe docente; apropriação e compreensão do $D L(n=4)$; incongruências $(n=2)$; o $D L$ não ter sido considerado na preparação do ano letivo $(n=5)$ e 28 subcategorias que serão exploradas de seguida. Relativamente à Q2, referente a possíveis soluções, surgiram 3 categorias principais (domínio formativo $(n=8)$, apoio emocional ( $n=2)$ e apoio logístico) e 11 subcategorias apresentadas de seguida.

A maior dificuldade identificada prendeu-se, segundo 10 dos participantes, com a falta de formação, sobre a qual 11 referiram apenas ter informação sobre o decreto, enquanto 5 referiram ter formação sobre o mesmo (as coordenadoras da EMAEI e 1 docente de educação especial). Ainda, alguns participantes especificaram os domínios em que consideravam a falta de formação ser mais problemática, nomeadamente: na aplicação da flexibilização curricular $(n=3)$ que se refere à aplicação do DL 55/2018; em técnicas de dinamização de estudo e das aulas (n=1) (e.g., "A falta de formação (...) porque isto vai implicar a aplicação de novas técnicas, da flexibilização curricular ... de métodos, de dinamização de estudo (...) e de dar as aulas"); para inovar as suas práticas (e.g., não dar as aulas apenas de modo expositivo) dada a necessidade na adequação do docente à sociedade atual e ao ensino do século XXI; e na abordagem multinível ( $n=1)$. Num estudo realizado em 2019, $57.81 \%$ dos inquiridos revelaram ter dificuldade ou não compreender o princípio da abordagem multinível (FEDERAÇÃO NACIONAL DA EDUCAÇÃO; FNE, 2019). Foi, ainda, mencionado, por uma DEE, a falta de formação na área de coadjuvação (possibilidade sugerida para colmatar as necessidades de apoio em contexto) e a dificuldade de alguns docentes em aceitar este tipo de apoio. Potenciar o trabalho em equipa e uma maior articulação entre profissionais $(n=5)$ foi destacado como uma medida atenuadora dos desafios do trabalho multidisciplinar no domínio do apoio logístico (e.g., "(...) acho que havendo uma articulação de todos teríamos muito mais sucesso e mudanças também no próprio percurso escolar dos alunos.").

Parece-nos pertinente refletir sobre a multidisciplinaridade imposta pelo DL e, considerando o seu enquadramento biopsicossocial, propomos que poderia ser mais eficaz uma abordagem transdisciplinar na qual se prima pela passagem de estratégias e partilha de conhecimento (CARVALHO et al., 2016). Isto implica também que sejam proporcionadas condições de cariz organizativo e administrativo nomeadamente através da disponibilização de recursos humanos suficientes e tempo para momentos de reunião 
e trabalho em equipa (BRUDER \& DUNST, 2008; GURALNICK, 2005; MOURATO, 2012 citados por CARVALHO et al., 2016), soluções também contempladas nos testemunhos dos participantes no domínio do apoio logístico.

A formação nos decretos-lei 54/2018 e 55/2018 (n=3) (e.g., "Primeiro, eu acho que deviam ter feito uma formação (...) sobre o decreto, sobre estratégias, sobre formas de abordar") e a sensibilização ( $n=5)$ (e.g., "É sensibilizar através de ações diversas que a equipa achar convenientes e adequadas ao contexto que tiver.") foram apontadas enquanto soluções no domínio formativo. Foi referido, por uma participante, que embora vá existindo formação, foram priorizados os elementos das direções e das EMAEI, sendo que os restantes docentes teriam de pagar a formação, algo que se recusam fazer. Ainda, uma DEE destacou a necessidade de estender esta formação também aos funcionários, visto estes também fazerem parte da comunidade escolar (e.g., "todo o resto do pessoal ainda não foi abrangido, porque isto faz parte de uma formação que não é só para os docentes, mas para toda a comunidade educativa. Mesmo a postura dos funcionários também tem de mudar.").

No entanto, a possibilidade de formação também foi caracterizada como um desafio considerando que, segundo os participantes, os docentes encaram as formações e sensibilizações extra e voluntárias como mais horas de trabalho e, dada a sua condição profissional, tal é um entrave à sua adesão (e.g., "Está a ser muito difícil porque os professores também já estão fartos de formações e de tempos extra e fora do horário de trabalho."). Esta condição profissional refere-se ao facto de existirem fatores a nível mais macrossistémico, que categorizamos como características da classe docente resultantes das condições de trabalho (e.g., congelamento de carreiras) que se refletem na forma como os docentes encaram a sua profissão e o seu papel atualmente. Neste sentido, referiram que os docentes estão desgastados $(n=5)$, assoberbados de trabalho $(n=3)$ (e.g., "Porque os professores de uma forma geral estão assoberbados de trabalho burocrático..."), desmotivados e descontentes ( $n=2$ ) o que causa não só resistência na adesão à formação e sensibilização existentes, como se pode refletir nas suas práticas. Ainda, foram mencionados adjetivos como desrespeitados para caracterizar a classe docente (e.g., "Houve muito trabalho para deitar ao lixo. Muitas reuniões feitas à pressa... com a sensação sempre de que estamos a fazer tudo mal e tudo a correr (...) acho que nós sentimo-nos um bocado desrespeitados."). 
http://dx.doi.org/10.5902/1984686X47438

Outra dificuldade identificada pela maioria dos participantes foi a falta de tempo, sendo que 4 participantes abordaram esta dificuldade de um modo generalizado, enquanto 7 participantes especificaram a falta de tempo para a apropriação do decreto e planeamento da implementação (e.g., "mas acho que o tempo de preparação foi curto, portanto isso teria sido necessário.") o que acaba por se traduzir numa dificuldade acrescida por estarem a pensar e agir em simultâneo, resultado também encontrado no estudo da FNE, no qual $91 \%$ dos participantes consideraram que não houve tempo suficiente para que as escolas aplicassem o DL (FNE, 2019). Esta dificuldade prende-se com uma outra também referida que é o facto de o decreto-lei não ter sido considerado na preparação do novo ano letivo $(\mathrm{n}=5)$ (e.g., "Isto foi lançado em julho, em período de... já de preparar o novo ano e ninguém teve em atenção este decreto-lei na preparação do novo ano letivo"), por exemplo, no que respeita à compatibilidade dos horários dos elementos da EMAEI. A falta de tempo para o trabalho colaborativo também foi referida no relatório da FNE, no qual $80 \%$ dos participantes mencionaram que não foram contempladas horas para este tipo de trabalho nos seus horários (FNE, 2019).

Ainda, referiram a falta de tempo para estar com os alunos em sala de aula de modo a corresponder às suas necessidades $(n=6)$ (e.g., "as aulas é o mesmo tempo que nós tínhamos e como estes meninos exigem uma atenção especial (...) Senti essa grande dificuldade que é falta de tempo para às vezes dar atenção a uns e a outros."); e 3 participantes salientaram como a falta de tempo para reflexão impacta negativamente na compreensão e implementação do decreto. Estes problemas acabaram por se traduzir em práticas sem a devida reflexão e planeamento, que não só colocaram em causa a eficácia da implementação da legislação como também comprometeram a vivência dos profissionais, principalmente, de acordo com o presente estudo, da classe docente. Neste sentido foram sugeridas, pelos profissionais, como possíveis soluções num domínio logístico, a atribuição de mais tempo no horário dos profissionais que permitisse a promoção de reflexão em grupo $(n=2)$ e dar tempo de adaptação $(n=2)$ na medida em que estes consideram que a partilha de experiências e dificuldades, e o planeamento conjunto são cruciais para a eficácia da implementação, assim como na influência da prática ao longo do tempo.

Além da falta de tempo, foi reportada também a falta de recursos humanos para corresponder às necessidades de apoio $(n=3)$ (e.g., "E temos poucos professores disponíveis para fazerem coadjuvação") e a falta de estruturas que acompanhem a 
http://dx.doi.org/10.5902/1984686X47438

legislação $(n=1)$. Para colmatar esta dificuldade, no âmbito de um apoio logístico, tal como referido anteriormente, os profissionais sugeriram a disponibilização de mais recursos humanos $(n=4)$ de modo a corresponder às necessidades dos alunos dentro da sala (e.g., "É o que eu digo, passava por mais professores junto deles... um trabalho mais colaborativo"). Apesar de ter sido mencionado que uma possível solução é a coadjuvação e o apoio dentro das salas, uma docente titular referiu que os professores já estão habituados a não ter apoio em contexto de sala de aula (e.g., "O $1^{\circ}$ ciclo já não está habituado a ter apoio para as medidas universais.").

Foi também destacada a dificuldade na demarcação das legislações anteriores e na mudança de paradigma $(n=4)$ (e.g., "Nós no início, e isso acho que é inevitável, colávamonos muito e ainda continuamos a fazê-lo, colávamo-nos um bocadinho ao 3"; "A dificuldade maior é muito esta: mudança de paradigmas."). Esta dificuldade na mudança de paradigma acaba por se refletir em práticas desadequadas ao novo enquadramento do sistema educativo, nomeadamente, por ainda não haver uma completa compreensão da responsabilidade por parte dos docentes do ensino regular sobre todos os alunos, incluindo os alunos que eram, anteriormente, da educação especial.

Outra dificuldade mencionada prendeu-se com o envolvimento de toda a comunidade educativa e da família. $\mathrm{O}$ facto de a inclusão depender de tantos agentes, a sua implementação torna-se difícil pois implica a agência por parte de todos. Isto foi considerado, pelos participantes, um desafio porque a nova definição de papéis $(n=8)$ implica um ajustamento por parte de todos (redefinição dos papéis quer da escola, quer dos docentes, técnicos e da família), que por vezes não está claro (e.g., "qual é o papel do professor da educação especial, porque há professores da educação especial, embora não haja crianças da educação especial") e um afastamento de modelos de intervenção focados no défice e na criança, responsáveis por uma intervenção focalizada de um para um que ocorria muitas vezes fora do seu contexto de sala de aula.

É de referir que, a 13 de setembro de 2019, foi promulgada a Lei 116/2019 que efetivou a primeira alteração, depois de múltiplas propostas dos diversos partidos políticos com assento parlamentar, do DL 54/2018. Algumas das dificuldades identificadas pelos profissionais à data das entrevistas, nomeadamente a definição de papéis encontra-se mais clarificada nesta recente legislação, nomeadamente no ponto 3 do artigo 9.. "[a] monitorização e avaliação da eficácia da aplicação das medidas seletivas é realizada pela equipa multidisciplinar de apoio à educação inclusiva, de acordo com o definido no 
http://dx.doi.org/10.5902/1984686X47438

relatório técnico-pedagógico" onde anteriormente se lia "pelos responsáveis da sua implementação" e, ainda, com a introdução do ponto 4 no artigo 8.. "[a] aplicação das medidas universais é realizada pelo docente titular do grupo/turma e, sempre que necessário, em parceria com o docente de educação especial, enquanto dinamizador, articulador e especialista em diferenciação dos meios e materiais de aprendizagem e de avaliação" (Lei 116/2019). Esta lei veio oficializar uma outra sugestão fornecida por uma coordenadora da EMAEI que se prendia com a necessidade de formação para toda a comunidade educativa, de forma gratuita: "[c]ompete ao Governo garantir os meios necessários para habilitar todos os trabalhadores com a formação específica gratuita de apoio à aprendizagem e à inclusão" (artigo $111^{\circ}$, ponto 6 ).

Ainda relacionado com esta definição de papéis, foi salientado como desafio o envolvimento da família $(\mathrm{n}=8)$, tendo sido mencionado por duas DEE e por uma psicóloga de contextos educativos o esforço que a escola faz para tornar os encarregados de educação mais empoderados e parte ativa no processo educativo da sua criança. Foi ainda referida, por uma entrevistada, a desvalorização da escolaridade e a desresponsabilização dos mesmos pela educação dos seus educandos, atribuindo essa responsabilidade à escola que, por sua vez, também é desvalorizada (e.g., "Portanto, a maioria dos pais não... não vai à escola, é raríssimo ir à escola. (...) não valorizam a escolaridade... nem o trabalho dos professores... acham e dizem mesmo isso que o papel da escola é educar"). Relativamente à participação da família, no estudo da FNE foram encontrados resultados consistentes com os nossos, sendo que $68.94 \%$ dos participantes considera que o grau de participação dos pais/encarregados de educação é nada ou pouco frequente (FNE, 2019). Embora o envolvimento da família tenha sido identificado como uma dificuldade no nosso estudo, por cerca de metade dos profissionais, nenhum dos entrevistados propôs qualquer solução para tentar atenuar esta falta de envolvimento e conseguir motivar os encarregados de educação para uma participação ativa no processo educativo e nas tomadas de decisão sobre a sua criança. Parece-nos então pertinente que a formação dos docentes também contemple conteúdos relativos a estratégias para articular com as famílias, e estratégias que os ajudem a lidar com situações adversas e complexas. Não obstante estas dificuldades identificadas pelos participantes, consideramos positivo o facto de o novo decreto ter previsto o apoio dos DEE, da EMAEI e de outros técnicos envolvidos na vida do aluno, que demonstra a valorização dada ao contributo de diferentes profissionais e de diferentes contextos no 
http://dx.doi.org/10.5902/1984686X47438

desenvolvimento da criança, característica de excelência do paradigma biopsicossocial (ENGEL, 1977).

Emergiu a categoria a que denominamos de dimensão pessoal dos alunos com necessidades de suporte à aprendizagem (NSA) que, no DL 3/2008, se encontravam abrangidos, de um modo geral, pelo artigo 21. Currículo específico individual (CEI) e a obrigatoriedade na permanência na sala de aula com a restante turma $(n=5)$. Esta dimensão surge como uma dificuldade na medida em que, segundo o DL 54/2018, estes devem permanecer maioritariamente em contexto de sala de aula. Neste sentido, os participantes consideraram que seria vantajoso, ao nível de apoio logístico, ser-lhes proporcionada mais autonomia para que pudessem decidir internamente em que medida os alunos estariam incluídos em contexto de sala de aula, considerando que são quem melhor os conhece $(n=2)$ (e.g., "E darem-nos mais autonomia, suficiente para conseguirmos analisar caso a caso.").

Ainda neste âmbito, destacaram a dificuldade na inclusão de alunos com a anterior medida CEI nas suas turmas de referência, especialmente com a progressão na escolaridade ( $n=3$ ) (e.g., "A nível de secundário... é um problema... é um problema porque as disciplinas são mais de cariz teórico, não é? (...) Mas torna-se complicada a inclusão, nesses casos."), por alguns alunos apresentarem características no seu perfil que dificultam estar tanto tempo dentro da sala $(n=7)$ (e.g., alunos com défices cognitivos muito acentuados; alunos com multideficiências cujo trabalho com eles passa apenas por estimulação sensorial) e por alunos se sentirem diferentes em relação aos colegas $(n=4)$, por exemplo por não saberem ler, e não quererem estar em contexto de sala de aula (e.g., "(...) alguns são adolescentes, sobretudo nessa idade, não querem apoio dentro da sala de aula, eles sentem-se diferentes dentro da sala de aula ao serem apoiados."). Referiu ainda que este último fator estaria a causar abandono escolar, embora houvesse esforços por parte da escola no sentido de atenuar esta implicação. Destacamos que, sendo um dos objetivos do novo quadro legal quebrar as barreiras da desigualdade para que também se combata este fenómeno, tal deve ser alvo de reflexão.

Outra dificuldade salientada prende-se com a dimensão pessoal dos docentes do regular. Foram referidos aspetos como a desresponsabilização dos docentes (do "regular") sobre os alunos que antes eram considerados da educação especial (n=5) (e.g., “(...) os professores, principalmente, continuam a achar que os miúdos com necessidades educativas especiais (...) são exclusivamente nossos da educação especial.”). Esta 
http://dx.doi.org/10.5902/1984686X47438

subcategoria foi referida por profissionais que não são docentes titulares nem diretores de turma, sendo que os DT e Dt referiram que, atualmente, se sentem igualmente responsáveis quando comparam a sua prática anterior à prática implicada com a nova legislação.

Outro aspeto mencionado foi a crença dos docentes sobre a sua autoeficácia se houver necessidade de pedir medidas seletivas ou adicionais $(n=2)$ (e.g., "Passa-se que eles terão de dizer que o aluno é identificado porque falharam todas as medidas universais e que o professor esteja assim com medo de ser apontado do porque é que falhou"). Embora esta categoria não fosse diretamente mencionada por nenhum DT ou Dt entrevistados, uma Dt fez uma partilha neste sentido: "Portanto, o professor titular, agora, é que tem a culpa no cartório de tudo (...) se o aluno falhar... ai a culpa é do professor titular porque não fez estas medidas todas, etc.". Ainda nesta linha de raciocínio, foi destacada a insegurança/desconforto em inovar $(n=4)$ (e.g., "E também a mudança cria, (...) muita insegurança e nem todas as pessoas querem assumir estes riscos, estão disponíveis para isso.").

Uma solução sugerida no domínio do apoio emocional $(n=2)$ foi a importância de trabalhar as relações para colmatar as dificuldades emergentes quer da instabilidade e insegurança, quer da exigência de trabalhar em equipa, particularmente através do estabelecimento de uma vinculação segura que permita aos agentes educativos sentiremse seguros e confiantes para que se sintam mais confortáveis em arriscar e implementar o decreto (e.g., "Os professores sentirem-se apoiados porque se não houver esta base de apoio, esta base de segurança, nós não conseguimos explorar. (...) Portanto, neste momento eles estão completamente inseguros (...) o nosso trabalho no terreno é: segurança."), e a importância de trabalhar o sentido de união/colaboração ( $n=3)$ (e.g., "neste momento os professores precisam que se sentem com eles (...) que thes expliquem, que thes mostrem que estamos juntos e que as coisas são simples"). É de salientar que um dos fatores que os participantes referiram ter tido um impacto positivo neste processo foi exatamente a partilha entre pares e outros profissionais, e a postura das lideranças.

Outras cinco dificuldades destacadas nesta categoria foram: o impacto das crenças dos docentes sobre os alunos $(n=2)$, destacando o impacto das mesmas não só nas suas práticas como nas suas atitudes perante os alunos (e.g., "alguns outra vez com ideias muito retrógradas, com uma visão de um ensino elitista, seletivo... continua a haver."); a 
resistência ao modelo novo $(\mathrm{n}=4)$; a formatação ao modelo antigo $(\mathrm{n}=6)$ (e.g., "Também habituados a outro tipo de... de pedagogia, vamos dizer assim. E ainda estamos um bocadinho formatados no modelo antigo") - uma docente titular também reportou esta dificuldade referindo-se, no entanto, aos DEE que mencionou não estarem habituados a trabalhar em contexto (e.g., "E mesmo isto para o professor da educação especial (...) não estão a conseguir entrar neste registo com muita facilidade também."); e a aceitação da coadjuvação ou do apoio à implementação pelo docente titular da disciplina $(\mathrm{n}=3)(\mathrm{e} . \mathrm{g}$., "O professor titular tem de aceitar, preparar as aulas em conjunto... não é fácil.").

A apropriação e compreensão do decreto $(n=4)$ surgiu como um desafio, sendo que esta apropriação, de acordo com os participantes, não se resume à apropriação por parte apenas dos profissionais como também da família (e.g., "Precisamente ainda na apropriação da legislação por parte de todos, todos, todos os agentes (...) professores (...) diretores de turma (...) pais"). Na literatura, encontraram-se dados que indicam que $59,26 \%$ dos professores consideram que não estão preparados para esclarecer os encarregados de educação (FNE, 2019) o que reforça, uma vez mais, a necessidade de formação.

Nesta categoria verificaram-se então três subcategorias: a falta de respostas/esclarecimento $(n=6)$ (e.g., "Porque mesmo lendo o manual de apoio à prática, mesmo lendo as $\mathrm{FAQs}^{7}$ continuamos com dúvidas (...) Mesmo em formações às quais eu assisti com as pessoas que desenharam este novo decreto, foram colocadas questões e não nos souberam responder..."); o desconhecimento sobre o decreto-lei $(\mathrm{n}=5)$ e o facto de alguns docentes, apesar do desconhecimento sobre a legislação, não procurarem mais informação restringindo-se ao que ouviram $(n=1)$ (e.g., "A dificuldade essencial é os colegas não terem lido o decreto-lei, nem saberem de que é que estamos a falar. (...) Então, alguém ouviu falar que, e eles nem procuram aquela informação na fonte"). Para colmatar estas dificuldades sugeriram, no domínio formativo, além de formação e sensibilização, a disponibilização de informação detalhada $(\mathrm{n}=3)$, clara e coerente (e.g., "Portanto, acho que no meio disto precisávamos de informações mais precisas, mais objetivas, de como operacionalizar tudo isto") - solução também sugerida para suprimir as dificuldades decorrentes das incongruências existentes/sentidas.

Estas, de acordo com os participantes, reportam-se a: incongruência entre as exigências a nível macro, nomeadamente a existência de avaliações externas e as normas do Júri Nacional de Exames, e as filosofias subjacentes à nova legislação $(\mathrm{n}=4)$ 
(e.g., "continuam a haver exames e provas de aferição e eu acho que isso acaba por ser quase uma incongruência entre aquilo que a lei prevê que é o sucesso dos alunos de acordo com aquilo que eles são capazes"); incongruência da postura das lideranças/inspeções ( $n=2$ ) (e.g., "enquanto que o Secretário de Estado diz "é um processo, vai-se fazendo", vem a equipa (...) dos inspetores das escolas e diz: mas a legislação diz isto e vocês ainda não estão a aplicar porquê?"), sendo que uma DEE alertou para o facto de as inspeções poderem servir como uma ferramenta para melhorar a qualidade das respostas (e.g., "até pegar no nosso projeto educativo e dizer assim: 0 vosso projeto é este, mas onde é que vocês podiam fazer a tal inclusão e eliminar as tais barreiras que nós não queremos?"). Concordamos que, tal como sugerido, o papel das inspeções poderá ser fundamental se realmente se centrar, além da documentação, nas práticas e no impacto das mesmas na comunidade escolar pois os momentos de supervisão poderão também traduzir-se em excelentes momentos de formação. Com a Lei 116/2019, foi especificada esta responsabilidade pertencente à Inspeção - Geral da Educação e Ciência (artigo 33.․․ Lei 116/2019).

Outra subcategoria ainda neste domínio das incongruências é a ambiguidade da legislação $(\mathrm{n}=1)$ que, de acordo com os entrevistados, por ser vasta e abrangente, permite múltiplas leituras e práticas distintas $(\mathrm{n}=3)$ (e.g., "E, de facto, o decreto (...) dá margem para todas estas interpretações, tem uma amplitude muito grande, é tudo muito universal e, portanto, dá margem (...) para toda uma série de interpretações”) que influencia a implementação do decreto.

Considerando esta falta de respostas e de esclarecimentos por parte das entidades competentes, referida pelos participantes, nomeadamente no que respeita às incongruências entre as filosofias subjacentes ao DL (e.g., respeito pela individualidade, pelo ritmo do aluno) e as exigências colocadas a nível macrossistémico (e.g., realização de avaliações externas), entre a postura da Inspeção-Geral da Educação (que, segundo alguns participantes, prioriza a formalização e não as práticas) e a posição das lideranças (que tranquilizam os profissionais salientando a ideia de continuidade e construção) e, ainda, entre as informações provenientes do Ministério da Educação e do DL (e.g., dislexias não carecerem de $\mathrm{RTP}^{8}$ ) e as normas do Júri Nacional de Exames (e.g., para ter tempo extra nos exames os alunos carecem de RTP), parece-nos pertinente que, previamente à publicação das normas, houvesse um entendimento entre as instâncias superiores sobre as exigências que se iriam colocar. Embora este tenha sido um ano 
http://dx.doi.org/10.5902/1984686X47438

experimental, como referido por alguns dos profissionais entrevistados, é de salientar que uma consistência e clareza entre as informações publicadas facilitariam não só as práticas, como também ajudaria os profissionais no domínio emocional, através da diminuição da incerteza e insegurança, pois, a falta de segurança causa não só desconforto em inovar (que reforça a dificuldade em se demarcarem dos decretos anteriores), como também pode gerar crenças negativas sobre a sua autoeficácia, tal como relatado por uma Dt.

Apesar de ter sido destacada amplamente a necessidade de segurança, formação, mais orientação e informação detalhada, foi referido por uma profissional que se deviam abolir burocracias $(n=1)$ e deveria existir um conjunto de documentos de base comuns para todos $(n=1)$ para que existisse mais coerência e um fio condutor nas práticas que as facilite, nomeadamente em processos de transferência (e.g., "neste momento a maior parte do trabalho que é feito depois fica em ata e as atas não transitam de escola para escola e (...) Devia haver ali um ponto comum para todos, pronto, haver ali uma orientação."). Esta situação também foi, de certa forma, acautelada com a introdução da obrigatoriedade do RTP acompanhar os alunos inclusive em situações de transição de escola (cf. ponto 1 do artigo 21., Lei 116/2019).

\section{Conclusão}

Esta visão holística dos alunos, assim como do seu percurso escolar (como um continuum) embora resulte de um longo percurso e de muito investimento na área da educação especial, traduz uma rutura com muitos dos ideais e das práticas preconizadas pela anterior lei especial para alunos especiais. Embora se tenham verificado alterações no DL anterior ao longo dos anos, este vigorou durante 10 anos. Portanto, com evoluções notórias, mas ainda não numa lógica completamente inclusiva, ao longo dos últimos 26 anos, nas nossas escolas foram instauradas e cristalizadas práticas que correspondiam aos ideais desses quadros legais mediante o conhecimento adquirido à época. Com a imposição de uma mudança de paradigma, considerada por alguns dos participantes, não apenas em valores como também em práticas, naturalmente surgem múltiplos desafios com os quais os profissionais dos contextos educativos tiveram e têm de lidar, verificando-se, por isso, ser imperativo dar-lhes voz para que as ações tomadas correspondam efetivamente às necessidades dos mesmos, potenciando a sua eficácia e sucesso e foi precisamente esse o objetivo deste estudo: auscultar os desafios que os/as profissionais 
http://dx.doi.org/10.5902/1984686X47438

dos contextos educativos sentiram e as soluções que identificaram como necessárias no momento de transição entre o quadro legal anterior e o atual. Apenas se os profissionais conseguirem ter sucesso, as nossas crianças e jovens o terão e, só assim, se conseguirá ter uma escola que responde a todos e a cada um. Esta é uma mudança que envolve a agência de todos nós, é uma mudança que parte de todos e que culmina em todos.

\begin{abstract}
"A inclusão é um valor comum porque a paz é um valor comum e a pobreza é um problema comum. A segregação não é a solução. Às vezes, a segregação pode ser disfarçada como uma boa intenção de integração. Se não dermos o passo da integração para a inclusão, não avançaremos para a prática real." (COSTA, p.26 cit. in EUROPEAN AGENCY, 2018).
\end{abstract}

\title{
Referências
}

ALVES, Ines. International Inspiration and National Aspirations: Inclusive Education in Portugal. International Journal of Inclusive Education, v. 23, n. 7-8, p. 862-875, 2019.

BARDIN, Laurence. Análise de Conteúdo. Lisboa: Edições 70, 2011.

BAUER, Martin W., \& GASKELL, George. Pesquisa Qualitativa com Texto, Imagem e Som: Um Manual Prático. Petropolis, RJ: Vozes Limitada, 2012.

CARVALHO, Leonor, ALMEIDA, Isabel. C., FELGUEIRAS, Isabel, LEITÃO, Sara, BOAVIDA, José, SANTOS, Paula C.,... FRANCO, Vitor. Práticas recomendadas em intervenção precoce na infância: Um guia para profissionais ( $1^{\mathrm{a}} \mathrm{ed}$.). Coimbra: Associação Nacional de Intervenção Precoce, 2016.

DIREÇÃO GERAL DA EDUCAÇÃO (2018). Para uma Educação Inclusiva - Manual de Apoio à Prática.

ELO, Satu, KYNGÄS, Helvi. The Qualitative Content Analysis Process. Journal of Advanced Nursing, 62(1), 107-115, 2007.

ENGEL, George L. The Need for a New Medical Model: A Challenge for Biomedicine. Science, 196(4286), 129-136, 1997. http://dx.doi.org/10.1126/science.847460

EUROPEAN AGENCY FOR SPECIAL NEEDS AND INCLUSIVE EDUCATION. Promoting Common Values and Inclusive Education: Reflections and Messages. (V. Soriano and G. Hughes, eds.). Odense, Denmark, 2018.

FEDERAÇÃO NACIONAL DA EDUCAÇÃO (2019). Consulta Nacional Educação Inclusiva 2019. Departamento de Informação e Imagem.

FREIRE, Sofia. Um Olhar sobre a Inclusão. Revista da Educação, XVI(1), 5-20, 2008.

LIMA, Jorge Ávila, PACHECO, José Augusto. Fazer Investigação. Contributos para a Elaboração de Dissertações e Teses. Porto: Porto Editora, 2006. 
Lei 116/2019 da Assembleia da República (2019). Diário da República: I série, n. 176 . Retirado de https://dre.pt/web/guest/pesquisa/-/search/124680588/details/maximized (acesso em: 15/06/2020)

PATTON, Michael Quinn. Qualitative Evaluation and Research Methods (p. 169-186). Beverly Hills, CA: Sage Publications, inc, 1990.

PEREIRA, Filomena. Educação Inclusiva: um imperativo ético. Jornal de Letras, de 12 de setembro de 2018.

PEREIRA, Filomena Oportunidades e Desafios dos DL54/2018 e DL55/2018, Porto, 2019.

POIRIER, Jean, CLAPIER-VALLADON, Simone. RAYBAUT, Paul. Histórias de Vida Teoria e prática. (2 ${ }^{\underline{a}}$ Ed.). Oeiras: Celta Editora, 1999.

Portaria n.ำ 275-A/2012 do Ministério da Educação e Ciência (2012). Diário da República: I

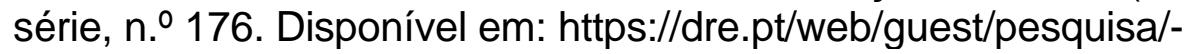

/search/351887/details/normal?|=1. Acesso em: 06/04/2021.

Portaria n. ํ 201-C/2015 do Ministério da Educação e Ciência (2015). Diário da República: I série, n.. 133. Disponível em: https://dre.pt/home/-/dre/69778954/details/maximized. Acesso em: 06/04/2021.

PORTUGAL. Decreto-lei 319/91 do Ministério da Educação (1991). Diário da República: I série A, n. 193. Disponível em: https://dre.pt/pesquisa/-/search/403296/details/maximized. Acesso em: 06/04/2021.

PORTUGAL. Decreto-lei 6/2001 do Ministério da Educação (2001). Diário da República: I série A, n. 15. Disponível em: https://dre.pt/pesquisa/-/search/338986/details/maximized. Acesso em: 06/04/2021.

PORTUGAL. Decreto-lei 281/2009 do Ministério da Saúde (2009). Diário da República: I

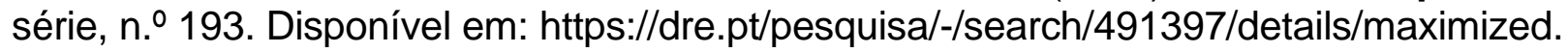
Acesso em: 06/04/2021.

PORTUGAL. Decreto-lei 54/2018 da Presidência do Conselho de Ministros (2018). Diário da República: I série, $\mathrm{n} . \stackrel{0}{129}$. Disponível em: https://dre.pt/home/-

/dre/115652961/details/maximized. Acesso em: 15/06/2020.

PORTUGAL. Decreto-lei 55/2018 da Presidência do Conselho de Ministros (2018). Diário da República: I série, $\mathrm{n} . \stackrel{0}{129}$. Disponível em: https://dre.pt/home/-

/dre/115652962/details/maximized. Acesso em: 15/06/2020.

PINTO, Paula C.; PINTO, Teresa J. Pessoas com Deficiência em Portugal: Indicadores de Direitos Humanos, 2018. Observatório Da Deficiência e Direitos Humanos.

https://doi.org/10.1016/j.ympev.2013.08.013

Recomendação n. ${ }^{\circ}$ 1/2014 do Ministério da Educação e Ciência - Conselho Nacional de Educação (2014). Diário da República: II série, n.ํ118. 


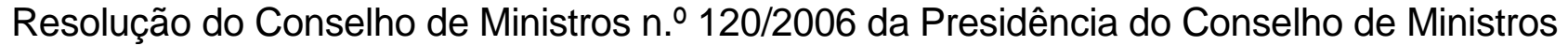
(2006). Diário da República: I série, n.ำ 183. Disponível em:

https://dre.pt/web/guest/pesquisa/-/search/541782/details/maximized. Acesso em: 06/04/2021.

Resolução da Assembleia da República n. 17/2015 da Assembleia da República (2015).

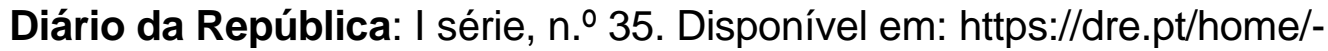

/dre/66536459/details/maximized?p_auth=7Qiip2TW. Acesso em: 06/04/2021.

SANCHES-FERREIRA, Manuela, SILVEIRA-MAIA, Mónica. ALVES, Sílvia. The Use of the International Classification of Functioning, Disability and Health, Version for Children and Youth (ICF-CY), Portuguese Special Needs Education Assessment and Eligibility Procedures: The Professionals' Perceptions. European Journal of Special Needs Education, 29(3), 327-343, 2014.

SHONKOFF, Jack P., MEISELS, Samuel J. Early Childhood Intervention: The Evolution of a Concept. In S. J. Meisels \& J. P. Shonkoff, Handbook of Early Childhood Intervention. (p. 3-31). New York, NY, US: Cambridge University Press, 1990.

\section{UNESCO (1994). Declaração de Salamanca sobre Princípios, Política e Práticas na}

Área das Necessidades Educativas Especiais. Disponível em:

https://unesdoc.unesco.org/ark:/48223/pf0000139394. Acesso em: 15/06/2020.

WATERS, Jaime. Snowball sampling: a cautionary tale involving a study of older drug users. International Journal of Social Research Methodology (p. 367-380), 2014.

WHO. International Classification of Functioning, Disability and Health for Children and Youth (ICF-CY). Geneva: World Health Organization, 2007.

\section{Notas}

${ }^{1} \mathrm{O}$ termo "crianças" reporta-se a indivíduos até aos 18 anos.

${ }^{2}$ CEE - Comunidade Económica Europeia (atual União Europeia)

${ }^{3}$ O termo "alunos" reporta-se a alunos e alunas.

${ }^{4}$ Sistema Nacional de Intervenção Precoce na Infância

${ }^{5}$ Classificação Internacional da Funcionalidade, Incapacidade e Saúde (OMS, 2001)

${ }^{6}$ Programa educativo individual

${ }^{7}$ Frequently Asked Questions, equivalente a "Perguntas frequentes".

${ }^{8}$ Relatório técnico-pedagógico: documento onde está fundamentada e definida a intervenção e as medidas a implementar. 